\title{
On the Inertia Term of Projectile's Penetration Resistance
}

\author{
Yu Shan, Haijun Wu, Fenglei Huang, and Jinzhu Li \\ State Key Laboratory of Explosion Science and Technology, Beijing Institute of Technology, Beijing 100081, China \\ Correspondence should be addressed to Haijun Wu; wuhjbit@hotmail.com
}

Received 2 November 2012; Accepted 4 January 2013

Academic Editor: Amit Bandyopadhyay

Copyright (C) 2013 Yu Shan et al. This is an open access article distributed under the Creative Commons Attribution License, which permits unrestricted use, distribution, and reproduction in any medium, provided the original work is properly cited.

\begin{abstract}
The effect of the target inertia term of rigid kinetic energy projectiles (KEP's) penetration resistance is investigated using nonlinear dynamic code LS-DYNA and four constitutive models. It is found that the damage number of target can be used to measure the influence of the inertia term. The smaller the damage number is, the less influence the inertia term has. The less dependent the resistance has on projectile velocity, the more accurate it is to treat the resistance as a constant. For the ogive-nose projectile with $\mathrm{CRH}$ of 3, when the target is aluminum, steel, or other metals, the threshold velocity for the constant resistance is at least $1258 \mathrm{~m} / \mathrm{s}$; when the target is concrete, rock, or other brittle materials, if the velocity of the projectile is greater than $400 \mathrm{~m} / \mathrm{s}$ or so, the damage number would be very large, and the penetration resistance would clearly depend on the projectile's velocity. The higher the elastic wave velocity is, the more penetration process is affected by the impact face.
\end{abstract}

\section{Introduction}

The calculation of a projectile's penetration depth has always been a hot topic of penetration mechanics, and it is very important to understand the penetration resistance. There have been many arguments about the contribution of the target strength term and the inertia term to the penetration resistance. The cavity expansion theory (CET) has been widely used for the calculation of antipenetration resistance of various targets (e.g., metal, concrete, and rock) [14]. According to CET, the penetration resistance can be expressed by

$$
F=\pi r^{2}\left(a Y+b \rho_{t} v^{2}\right)
$$

where $r$ and $v$ are radius and instantaneous velocity of the projectile, respectively. $Y$ and $\rho_{t}$ are yield strength and density of the target, respectively. Dimensionless coefficients $a$ and $b$ can be determined through CET calculation. Generally, $a$ ranges from 4 to 5 , while $b$ varies from 1 to 1.5 for spherical nosed projectile and about 0.1 for ogive-nosed projectiles [5]. Apparently, the penetration resistance consists of two terms: the quasistatic term $a Y$ (the target strength term) and the dynamic term $b \rho_{t} v^{2}$ (the target inertia term). The dependence of the penetration resistance on the projectile's velocity would become obvious when the projectile's velocity is greater than $400 \mathrm{~m} / \mathrm{s}$ according to CET theory for rock and concrete materials $[1,3]$.

However, when Batra and Wright [6] investigated the retarding force of an infinitely long spherically nosed rigid projectile penetrating into a rigid plastic target through a set of $2 \mathrm{D}$ simulations, they found $a=3.903$ and $b=0.0773$ when describing the retarding force using (1). The shape coefficient $b$ is much smaller than CET calculation result; that is, CET model overestimates the contribution of the target inertia term. Hill [7] and Rapoport and Rubin [8] adopted a two-dimensional approach, which is different from the one-dimensional CET model, to describe the penetration resistance. They found that there is a critical velocity $v_{c}$ below which the penetration resistance is due solely to the resistance of plastic flow in the target and velocity independent. The experimental records of penetrators' decelerationtime history of Forrestal et al. [9] have approved this. The influence of the inertia term becomes important, and the penetration resistance becomes velocity dependent when the penetrator's velocity is greater than $v_{c}$. Rosenberg and Dekel [5] analyzed many kinds of numerical simulations of rigid projectiles with different nose shapes penetrating into metal described by elastic-perfectly plastic constitutive model. They considered penetration velocities in aluminum up to about $1.5 \mathrm{~km} / \mathrm{s}$ and concluded that the penetration resistance is 
insensitive to the penetration velocity. As for concrete target, Rosenberg and Dekel [10] studied the experimental data of penetration depths versus impact velocities and found that $v_{c}$ is no less than $1200 \mathrm{~m} / \mathrm{s}$. Li and Chen [11] got the threshold impact velocity $v_{c}$ applicable for the assumption of constant penetration resistance by impulse analysis. As with the conclusions of Rosenberg and Dekel [10], they found that $v_{c}$ depends on the target strength and the projectile nose shape. For ogive-nose projectile with a $3 \mathrm{CRH}$ (caliberradius-head) and $36.2 \mathrm{MPa}$ concrete, $v_{c}$ is $1186.4 \mathrm{~m} / \mathrm{s}$.

In general, there is no unified conclusion about whether the target inertia term of the penetration resistance should be considered when the projectile's velocity is in the range of $400-1300 \mathrm{~m} / \mathrm{s}$. For the terminal ballistics effects of the penetrator, most of the researchers focus on the penetration depth and residual velocity of the projectile instead of the projectile's deceleration-time history. In this study, ogive-nose projectiles penetrating into different targets were investigated with LS-DYNA 2D. By changing constitutive model, strength and density of the targets, the inertia term's contribution to different targets' antipenetration resistance, and corresponding characterization parameter were investigated. At last, the relationship between the targets elastic wave velocity and the sphere of influence of impact face was demonstrated.

\section{Numerical Simulation and Analysis}

2.1. Deceleration-Time History of Rigid Projectile Penetrating into Concrete. A set of finite element simulations were carried out on the experiments of Forrestal et al. [9]. The projectiles are dimensioned in Figure 1, and the cone at the end of the projectile was simplified into a cylinder to eliminate its influence on the penetration resistance. The grid size for finite element analysis is $0.26 \mathrm{~cm}$. Solid construction was employed because we did not know the geometric dimensioning of the hollow part of the projectile, and the density was adjusted to $6.03 \mathrm{~g} / \mathrm{cm}^{3}$ to ensure the correct weight for the projectile. Although this affects the wave velocity which in turn influences the high frequency response of the penetrator, we focus on its rigid body response so as to compare with the measure data, and this adjustment in mass density is reasonable. The target was modeled as an $800 \mathrm{~cm}$ deep and $152 \mathrm{~cm}$ in diameter block which is large enough to be considered as semi-infinite. To improve calculation efficiency, a gradually variational grid scheme was adopted. We use fine grids $(0.32 \mathrm{~cm})$ at the central zone of the target, up to a distance of three times projectile radiuses from the axis. Lagrange processor was used for projectile and target, and the projectile was simplified as rigid body with Young's modulus $(E) 206 \mathrm{GPa}$, Poisson's ratio (v) 0.28 . According to $[3,4]$, friction has little effect on the penetration depth when the striking velocity of the penetrator is low, so it is neglected.

The accuracy of FEM (finite element method) simulations depends heavily on the constitutive model. Due to the simple mechanical property of the metal, the elastic-perfectly plastic model adopted by Rosenberg and Dekel [5] can provide a good description of the mechanical property of the metal which has small strain sensitivity and strain-rate sensitivity;
TABLE 1: Material constants for the HJC model of $23 \mathrm{MPa}$ concrete.

\begin{tabular}{lcccc}
\hline$\rho_{t}\left(\mathrm{~kg} \cdot \mathrm{m}^{-3}\right)$ & $E(\mathrm{GPa})$ & $G(\mathrm{GPa})$ & $f_{c}(\mathrm{MPa})$ & \\
\hline 1970 & 13.8 & 7.5 & 23 & \\
$v$ & $A$ & $B$ & $C$ & $N$ \\
0.2 & 0.79 & 1.6 & 0.007 & 0.61 \\
\hline
\end{tabular}

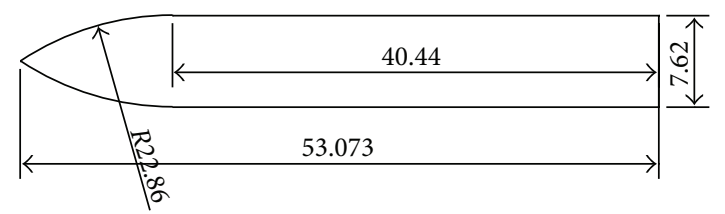

FIgURE 1: Projectile geometries [9] (unit: $\mathrm{cm}$ ).

so, their conclusions are suitable for these target materials. On the other hand, brittle materials like concrete have massive pores, hard aggregates, cement, and water. Their strength has a clear dependence on the confining pressures and strain rate. Although it is still a challenge to describe all the dynamic behavior, several dynamic constitutive models of concrete have been developed to describe various damage and failure behaviors of concrete during the penetration process. Holmquist et al. [12] developed the HJC (HolmquistJohnson-Cook) constitutive model for concrete subjected to large strains, high strain rates, and high pressures. This model can be used to exactly predict penetration depth and the residual velocity of the projectile, and it has been widely used in the numerical simulation. Taylor et al. [13] proposed a computational constitutive model which treats the dynamic fracture process in rock as a continuous accrual of damage, where the damage mechanism has been attributed to the microcracking in the rock medium. This model is applicable to the prediction of dynamic fracture behavior of rock and concrete. HJC model was adopted in our study. According to $[9,12]$, material model parameters were determined, which are listed in Table 1.

The penetration depths of the simulations are 62.34 , 100.32 , and $120.63 \mathrm{~cm}$ when the impact velocities were 250 , 336.6 , and $378.6 \mathrm{~m} / \mathrm{s}$, and the corresponding experimental data were 62, 93, and $118 \mathrm{~cm}$ [9], respectively. Figure 2 shows the deceleration-time history of the projectile with $250 \mathrm{~m} / \mathrm{s}$ striking velocity, and it can be seen that the simulation data is consistent with the experimental data. Both penetration depth and deceleration history prove that the FEM model and the parameters are valid. It is also interesting to note that decelerations are quite constant; that is, the inertia term has little influence on the penetration resistance within this velocity range.

Using the same FEM model, we got the deceleration history of penetrator with striking velocities $\left(v_{0}\right)$ of 800 , $1200 \mathrm{~m} / \mathrm{s}$, as can be seen from Figure 3, which also contains the velocity-time history of penetrator with $1200 \mathrm{~m} / \mathrm{s}$ striking velocity. The velocity-time history and deceleration history of $1200 \mathrm{~m} / \mathrm{s}$ penetrator show that the penetration resistance significantly increases with the increase of the penetrator velocity when the velocity of the penetrator is higher than $370 \mathrm{~m} / \mathrm{s}$ or so. Gao et al. [14] measured the deceleration 


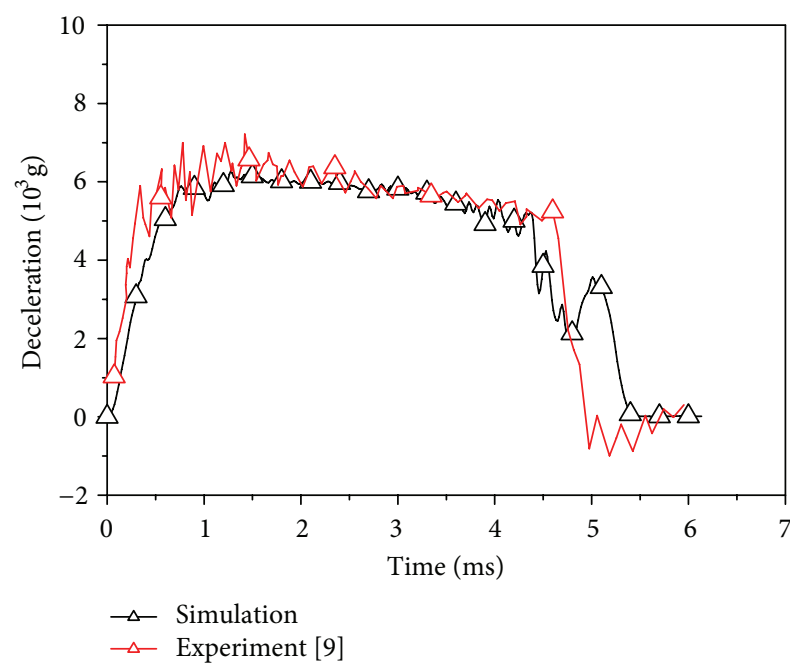

Figure 2: Deceleration versus time.

history of ogive-nose projectile with striking velocity up to $763 \mathrm{~m} / \mathrm{s}$ by experiments. Their experiment data show that the deceleration cannot be treated as a constant if the striking velocity is $666 \mathrm{~m} / \mathrm{s}$ or $763 \mathrm{~m} / \mathrm{s}$ (Figures 2 and 3 of [14]), and this trend is consistent with our simulations. There are two reasons for this result. First, as can be seen from (1), the inertia term increases as the projectile's velocity increases. Second, according to HJC model, the dynamic yield strength of the concrete can be formulated as

$$
\frac{\sigma_{Y}}{f_{\mathrm{c}}}=\left[A(1-D)+B\left(\frac{p}{f_{c}}\right)^{N}\right]\left[1+C \ln \dot{\varepsilon}^{*}\right],
$$

where $D, \dot{\varepsilon}^{*}$, and $p$ are damage parameter, dimensionless strain rate, and pressure, respectively. Other parameters are shown in Table 1. Obviously, the dynamic yield strength of the concrete is sensitive to pressure and strain rate. The increasing of the projectile's velocity would lead to the increasing of strain rate $\dot{\varepsilon}^{*}$ and the pressure acting on the concrete around the nose of projectile, which in turn would cause the increasing of the target strength and the penetration resistance.

To get rid of the influence of target constitutive model on our conclusion, the TCK (Taylor-Chen-Kuszmaul) model for $40 \mathrm{MPa}$ concrete was used, and the corresponding parameters are shown in Table 2 [15], where $K$ and $K_{\text {IC }}$ are bulk modulus and fracture toughness; $k$ and $m$ are material constants which can be determined by tensile test. The simulation results are shown in Figure 4, which contain deceleration history of projectiles with three kinds of different striking velocities and velocity-time history of projectile with $1200 \mathrm{~m} / \mathrm{s}$ striking velocity. They show that the penetration resistance has a clear dependence on the projectile's velocity when the projectile's striking velocity is $800 \mathrm{~m} / \mathrm{s}$ or $1200 \mathrm{~m} / \mathrm{s}$. From the velocity-time history and deceleration-time history of projectile with $1200 \mathrm{~m} / \mathrm{s}$ striking velocity, we can see that the threshold $v_{c}$ for constant penetration resistance raises to about $600 \mathrm{~m} / \mathrm{s}$, because of the increase of the target strength.

Based on the simulation results with the previous two constitutive models above, it can be concluded that for

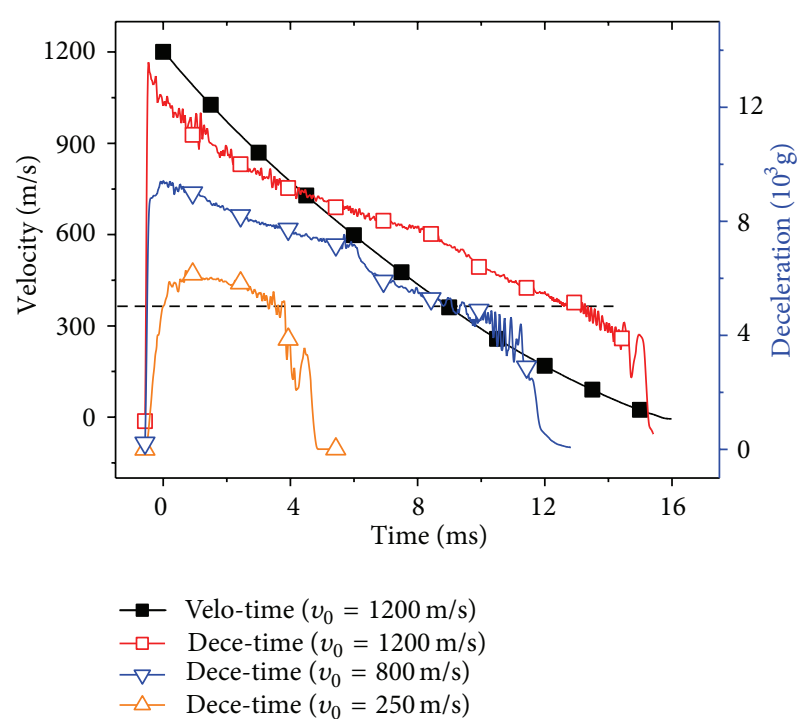

Figure 3: Deceleration and velocity versus time (23 MPa concrete, HJC model).

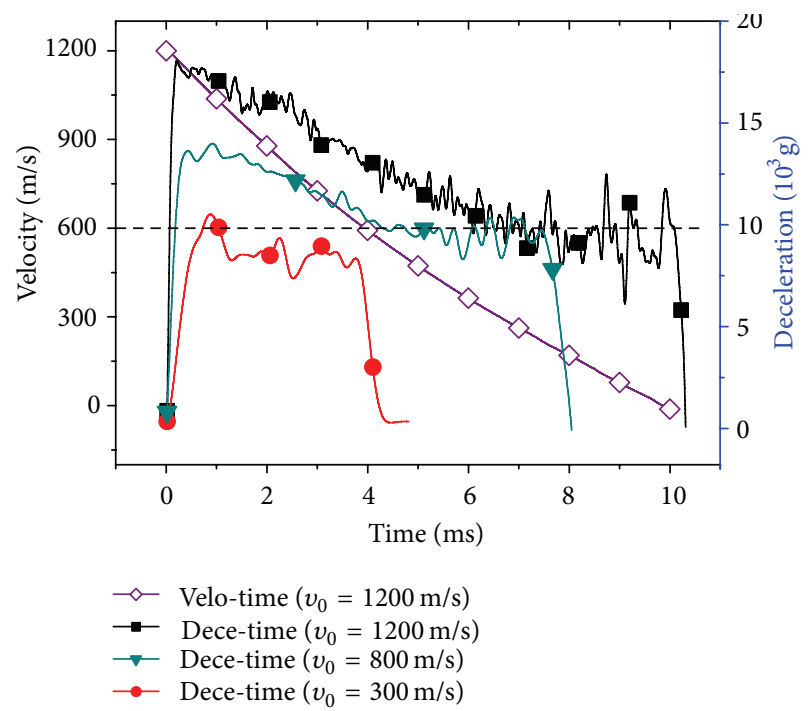

FIGURE 4: Deceleration \& velocity versus time (40 MPa concrete, TCK model).

concrete target, the inertia term has so little contribution to the penetration resistance that it can be neglected when the projectile's velocity is small. But if the striking velocity exceeds the threshold $v_{c}$ (for ogive-nose projectile with $\mathrm{CRH}$ of 3 , it normally ranges from 400 to 600 or so), the dependence of penetration resistance on projectile velocity is very clear and the inertia term should be considered.

\subsection{Deceleration-Time History of Rigid Projectile Penetrating} into Aluminum. For the metal target, Rosenberg and Dekel [5] have conducted a lot of interesting studies based on elastic-perfectly plastic constitutional model, but many metal targets have obvious strain-hardening effects and strain-rate effects in reality. Whether their conclusions are valid still needs research. Forrestal et al. [4] did a set of experiments 
TABLE 2: Material constants for the TCK model of $40 \mathrm{MPa}$ concrete.

\begin{tabular}{lcccc}
\hline$\rho_{t}\left(\mathrm{~kg} \cdot \mathrm{m}^{-3}\right)$ & $E(\mathrm{GPa})$ & $G(\mathrm{GPa})$ & $K(\mathrm{GPa})$ & $f_{c}(\mathrm{MPa})$ \\
\hline 2525 & 20.68 & 8.76 & 10.77 & 40 \\
$v$ & $k\left(\mathrm{~m}^{-3}\right)$ & $m$ & $\beta$ & $K_{\mathrm{IC}}\left(\mathrm{MPa} \cdot \mathrm{m}^{1 / 2}\right)$ \\
0.18 & $5.75 \times 10^{21}$ & 6 & 0.5 & 2.747 \\
\hline
\end{tabular}

TABle 3: Power-law constitution parameters of 7075-T651 aluminum [4].

\begin{tabular}{lcccc}
\hline$\rho_{t}\left(\mathrm{~kg} \cdot \mathrm{m}^{-3}\right)$ & $E(\mathrm{GPa})$ & $N$ & $Y(\mathrm{MPa})$ & $v$ \\
\hline 2710 & 73.1 & 0.089 & 448 & 0.33 \\
\hline
\end{tabular}

of steel projectile penetrating into 7075-T651 aluminum which have obvious strain-hardening effects. The power-law plasticity constitute model for this material can be formulated as

$$
\sigma= \begin{cases}E \varepsilon, & \sigma \leq Y \\ Y\left(\frac{E \varepsilon}{Y}\right)^{N}, & \sigma>Y\end{cases}
$$

where $\sigma, \varepsilon, Y$, and $N$ are stress, strain, initial yield stress, and hardening exponent, respectively, and the specific values are listed in Table 3. Lagrange algorithm was used for the projectile and the target. Erosion criterion of maximum principal strain was introduced to delete the target mesh with particularly large deformation. In this set of simulations, the diameter, length, mesh size, and $\mathrm{CRH}$ of the rigid projectile are $7.11 \mathrm{~mm}, 82.91 \mathrm{~mm}, 0.3 \mathrm{~mm}$, and 3, respectively. The target is a $22.9 \mathrm{~cm}$ long cylinder with diameter of $15.2 \mathrm{~cm}$. The gradually variational grid scheme was used, and the size of the fine grids at the center of the target is $0.25 \mathrm{~mm}$.

Through the simulation, we got that the penetration depth of projectiles with $372,695,978$, and $1258 \mathrm{~m} / \mathrm{s}$ striking velocities are $29,72,125$, and $196 \mathrm{~mm}$, while the corresponding experimental data are 26, 70, 127, and $209 \mathrm{~mm}$, respectively [4]. The simulation results are in good agreement with the experiment data. Figure 5 shows the deceleration history of projectile with four different striking velocities. Figures 5(a) and 5(b) are the results of numerical simulation and CET calculations (which neglect the compressibility of aluminum and friction), respectively. Figure 5(a) shows that the penetration resistance keeps increasing at the preliminary stage of the penetration because of the influence of the projectile's entry process and the impact face. The resistance is approximately constant when stable penetration stage comes. The constant deceleration is around $4.6 \times 10^{5} \mathrm{~g}$, which is greater than the result of Rosenberg and Dekel $\left(4.08 \times 10^{5} \mathrm{~g}\right)$ [5]. This is because the latter is the average deceleration of the whole penetration process. It can be seen from Figure 5(b) that the penetration resistance obviously depends on the projectile's velocity, especially when the striking velocity is high. This trend is inconsistent with the trend shown in Figure 5(a). In addition, Figure 5(a) shows that the time when the decelerations reach their constant values are 123.99 and 91.99 us for projectile with striking velocities of 978 and $1258 \mathrm{~m} / \mathrm{s}$, and the penetration depths corresponding to

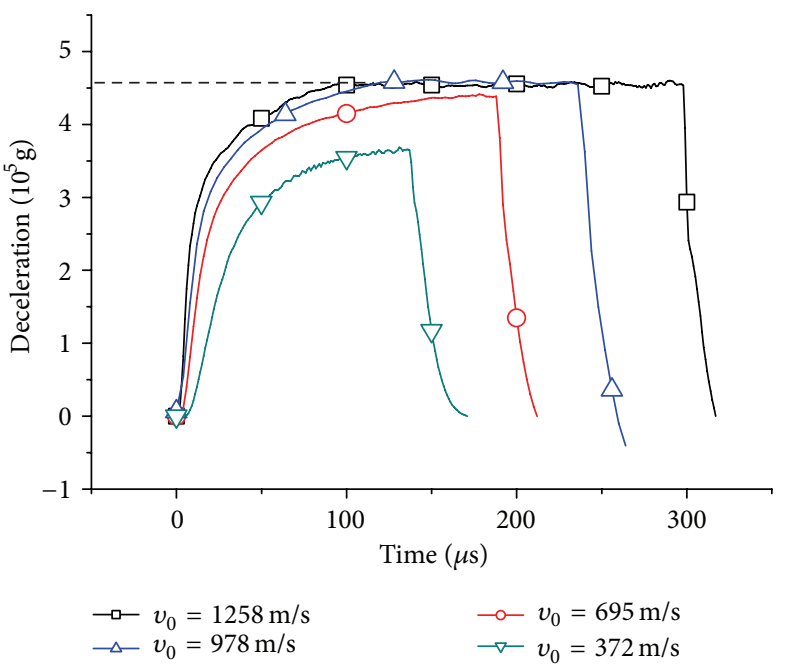

(a) Simulation results

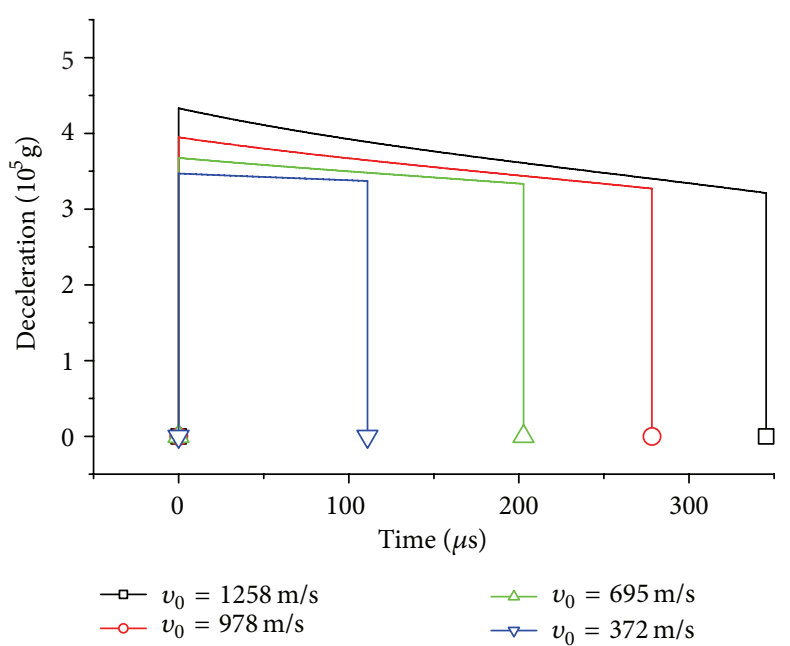

(b) Calculation results based on CET [4]

FIGURE 5: Deceleration versus time of projectile with different striking velocities.

the moment are 94.78 and $100.4 \mathrm{~mm}$, respectively. These two penetration depths, which are far greater than the length of the projectile nose $(11.79 \mathrm{~mm})$, account for $75 \%$ and $51 \%$ of their total penetration depth. That is to say, the impact face affects the penetration resistance for most of the penetration process, but the CET-based methods shown in [4] entirely neglect the influence of the impact face and entry process. Based on the simulation results shown in Figure 5(a), we formulated the penetration resistance of projectile of $1258 \mathrm{~m} / \mathrm{s}$ striking velocity with (1) then got $a=4.64$ and $b=0.0022$ (assuming that $Y=0.6 \mathrm{GPa}[5]$ ), while $a=4.609$ and $b=0.16$ according to the CET shown in [4]. Obviously, compared with the numerical simulation, the CET based methods overestimate the contribution of inertia term to the total penetration resistance. This conclusion agrees with 


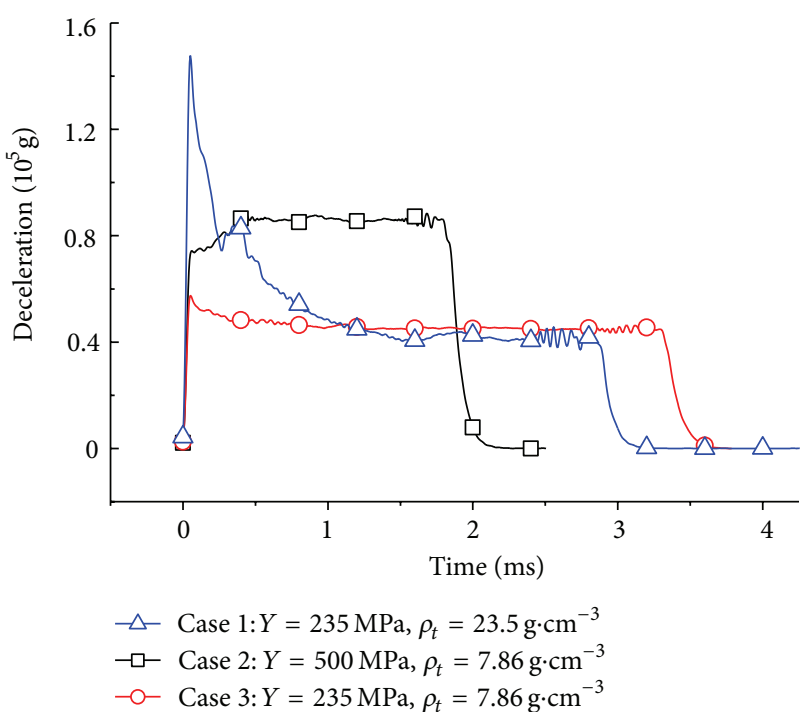

FIGURE 6: Deceleration versus time of projectile penetrating into steel target (all striking velocity $=1500 \mathrm{~m} / \mathrm{s}$ ).

the founding of Batra and Wright [6]. Hence, although CET based methods can be used to calculate the penetration depth exactly, they cannot provide an accurate description of the deceleration-time history for the penetrator.

\subsection{Deceleration-Time History of Rigid Projectile Penetrating} into Steel. Based on the FEM model shown in Section 2.1, using elastic-perfectly plastic constitutive model $(E=$ $200 \mathrm{GPa}$ and $v=0.28$ ) then just changing the strength or density of the target, we get deceleration histories of projectiles penetrating into three different steel targets, as shown in Figure 6. In Figure 6, the target of Case 1 is a virtual steel material whose strength is $235 \mathrm{MPa}$, density is $23.5 \mathrm{~g} \cdot \mathrm{cm}^{-3}$, and the targets of Case 2 and Case 3 are Q500 and Q235, respectively. The simulation results of Case 2 and Case 3 show that the penetration resistance keeps constant during the stable penetration stage. However, Case 3 does not show the influence of the entry process and impact face, and it is different from the results of aluminum target shown in Figure 5(a). This is because Q235 has lower strength and higher density than 7075-T651 aluminum, and the inertia term of Q235 target is so strong that it obscures the influence of the impact face. If we increase the strength of the steel to $500 \mathrm{MPa}$, the strength term obscures the influence of inertia term then, as shown in Case 2, and this curve is very similar to that of aluminum shown in Figure 5(a). If we increase the density of the steel to $23.5 \mathrm{~g} \cdot \mathrm{cm}^{-3}$, the target inertia term would play an important role in the penetration resistance, as shown in Case 1. That is to say, even if elastic-perfectly plastic model is used, the penetration resistance would show a clear dependence on the projectile velocity when the target density is high enough.

From Figures 3, 5(a), and 6, we can see that there is a big difference between concrete and metal (e.g., aluminum and steel) when considering the inertia term's contribution to the target's antipenetration resistance. The next issue is to find the
TABLE 4: Normalized penetration depth when the penetration resistance just reaches constant.

\begin{tabular}{lccccc}
\hline Target & C23 & C40 & Aluminum & Q235 & Q500 \\
\hline$P$ & 2.49 & 2.85 & 13.73 & 7.10 & 7.12 \\
\hline
\end{tabular}

reason. According to (1), the effect of the inertia term can be formulated by

$$
\frac{\text { inertia term }}{\text { strength term }}=\frac{b \rho_{t} v^{2}}{a \mathrm{Y}}=\lambda D \text {, }
$$

where damage number $D=\rho_{t} v^{2} / Y$ and $\lambda=b / a$. As mentioned earlier, $b$ depends on the nose shape of the penetrator and $a$ is in the range of 4-5. Thus, the damage number $(D)$ of the target material can be used to characterize the influence of the inertia term's contribution to target's antipenetration resistance. The smaller the damage number is, the less influence the inertia term has. The targets used in our simulation include $23 \mathrm{MPa}$ concrete, Q235 steel, Q500 steel, and aluminum, and the corresponding damage numbers are $162,57,27$, and 7.6 when the projectile's velocity is $1300 \mathrm{~m} / \mathrm{s}$. These damage numbers reduce in turn, and the deceleration histories in Figures 3-6 also show that the inertia term's influences reduce in turn. Substituting $a=4.64$ and $b=0.0022$ got in Section 2.2 into (4), we get that the ratio of inertia term and strength term is $0.36 \%$ for aluminum target; so, the inertia term can be neglected. The damage number of concrete is at least an order of magnitude greater than that of metals; as a result, the inertia term's contribution to concrete target's antipenetration resistance is much greater than that of metallic target. Thus, for the ogive-nose projectile with $\mathrm{CRH}$ of 3, when the targets are aluminum, steel, and other metals, the threshold velocity for the constant resistance is at least $1300 \mathrm{~m} / \mathrm{s}$; when the targets are concrete, rock, and other brittle materials, if the velocity of the projectile is higher than $400 \mathrm{~m} / \mathrm{s}$ or so, the damage number would be very large, and the penetration resistance would clearly depend on the projectile's velocity.

2.4. Sphere of Influence of Impact Face. As shown in Figures 3, 4, and 5(a), it will take some time for the penetration resistance to reach its constant value. This is because of the influence of the impact face and the entry process. Table 4 lists the normalized penetration depth $P$ (dividing the real penetration depth by projectile diameter $d$ ) of projectile whose penetration resistance just reaches its constant value. For concrete, $P$ is consistent with the crater depth $(2.3 d)$ given by Li and Chen [16], while for metallic targets, $P$ is 7.1 at least. This is caused by the difference of elastic wave speeds, which are 2800, 5044 and $5194 \mathrm{~m} / \mathrm{s}$ for concrete, Q235 steel and aluminum, respectively. The higher the elastic wave velocity is, the more penetration process is affected by the impact face. The big difference of $P$ between aluminum and steel is caused by the difference of constitutive models adopted, which are power-law-plastic and elastic-perfectly plastic, respectively. 


\section{Conclusions}

The inertia term's contribution to rigid projectile's penetration resistance is investigated using nonlinear dynamic program LS-DYNA. It is found that the damage number of the target material can be used to characterize the inertia term's contribution to penetration resistance, and the elastic wave velocity of the target material can be used to estimate the penetration process affected by the impact face. Four constitutive models are used to compare with each other to eliminate their influence on the results; thus, our conclusions have universal applicability. The paper clarifies the argument about the effect of the target inertia term of rigid KEP's penetration resistance and deepens our understanding of the variation of penetration resistance during the penetration process.

\section{Acknowledgments}

The authors are grateful to the constructive suggestions from Dr. Qingming Li of The University of Manchester and the financial support from the Defense Industrial Technology Development Program (C152011001).

\section{References}

[1] M. J. Forrestal, "Penetration into dry porous rock," International Journal of Solids and Structures, vol. 22, no. 12, pp. 1485-1500, 1986.

[2] M. J. Forrestal and D. Y. Tzou, "A spherical cavity-expansion penetration model for concrete targets," International Journal of Solids and Structures, vol. 34, no. 31-32, pp. 4127-4146, 1997.

[3] Y. Shan, H. J. Wu, F. L. Huang, and X. X. Zhang, "Study on the behavior of projectile shank friction penetrating into concrete," Transactions of Beijing Institute of Technology, vol. 32, no. 1, pp. 12-17, 2012 (Chinese).

[4] M. J. Forrestal, V. K. Luk, Z. Rosenberg, and N. S. Brar, "Penetration of 7075-T651 aluminum targets with ogival-nose rods," International Journal of Solids and Structures, vol. 29, no. 14-15, pp. 1729-1736, 1992.

[5] Z. Rosenberg and E. Dekel, "The penetration of rigid long rods-revisited," International Journal of Impact Engineering, vol. 36, no. 4, pp. 551-564, 2009.

[6] R. C. Batra and T. W. Wright, "Steady state penetration of rigid perfectly plastic targets," International Journal of Engineering Science, vol. 24, no. 1, pp. 41-54, 1986.

[7] R. Hill, "Cavitation and the influence of headshape in attack of thick targets by non-deforming projectiles $\uparrow$," Journal of the Mechanics and Physics of Solids, vol. 28, no. 5-6, pp. 249-263, 1980.

[8] L. Rapoport and M. B. Rubin, "Separation and velocity dependence of the drag force applied to a rigid ovoid of Rankine nosed projectile penetrating an elastic-perfectly-plastic target," International Journal of Impact Engineering, vol. 36, no. 8, pp. 1012-1018, 2009.

[9] M. J. Forrestal, D. J. Frew, J. P. Hickerson, and T. A. Rohwer, "Penetration of concrete targets with deceleration-time measurements," International Journal of Impact Engineering, vol. 28, no. 5, pp. 479-497, 2003.
[10] Z. Rosenberg and E. Dekel, "The deep penetration of concrete targets by rigid rods-revisited," International Journal of Protective Structures, vol. 1, no. 1, pp. 125-144, 2010.

[11] J. C. Li and X. W. Chen, "Threshold impact velocity under the assumption of constant resistive force in the penetration of a rigid projectile," in Proceeding of the 25th International Symposium on ballistics, pp. 1140-1148, Beijing, China, 2010.

[12] T. J. Holmquist, G. R. Johnson, and W. H. Cook, "A computational constitutive model for concrete subjected to large strains, high strain rates, and high pressures," in Proceeding of the 14th International Symposium on Ballistics, pp. 591-600, Quebec, Canada, 1993.

[13] L. M. Taylor, E. P. Chen, and J. S. Kuszmaul, "Microcrackinduced damage accumulation in brittle rock under dynamic loading," Computer Methods in Applied Mechanics and Engineering, vol. 55, no. 3, pp. 301-320, 1986.

[14] S. Q. Gao, H. P. Liu, and L. Jin, "A fuzzy model of the penetration resistance of concrete targets," International Journal of Impact Engineering, vol. 36, no. 4, pp. 644-649, 2009.

[15] Y. Liu, A. Ma, and F. Huang, "Numerical simulations of obliqueangle penetration by deformable projectiles into concrete targets," International Journal of Impact Engineering, vol. 36, no. 3, pp. 438-446, 2009.

[16] Q. M. Li and X. W. Chen, "Dimensionless formulae for penetration depth of concrete target impacted by a non-deformable projectile," International Journal of Impact Engineering, vol. 28, no. 1, pp. 93-116, 2003. 

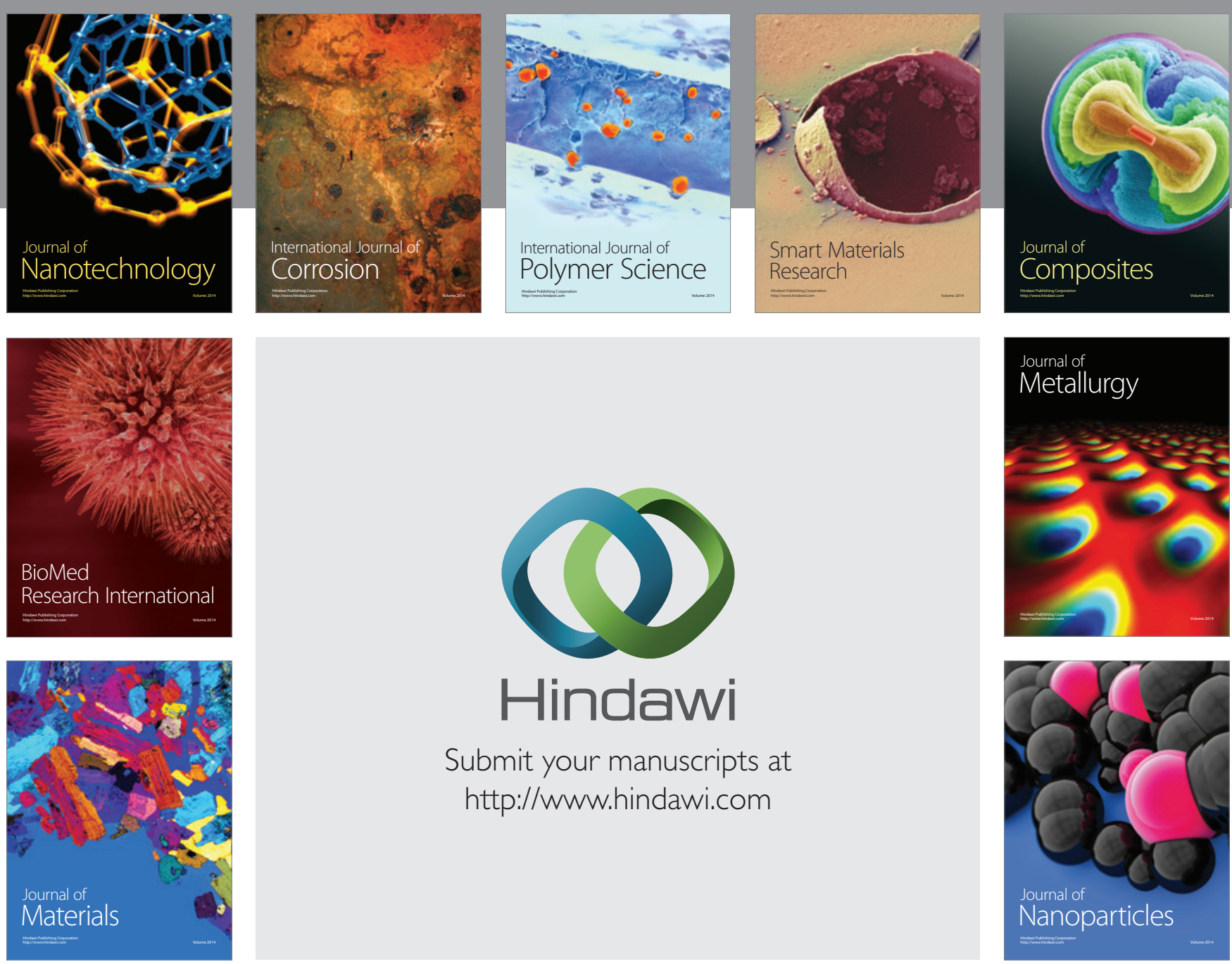

Submit your manuscripts at http://www.hindawi.com
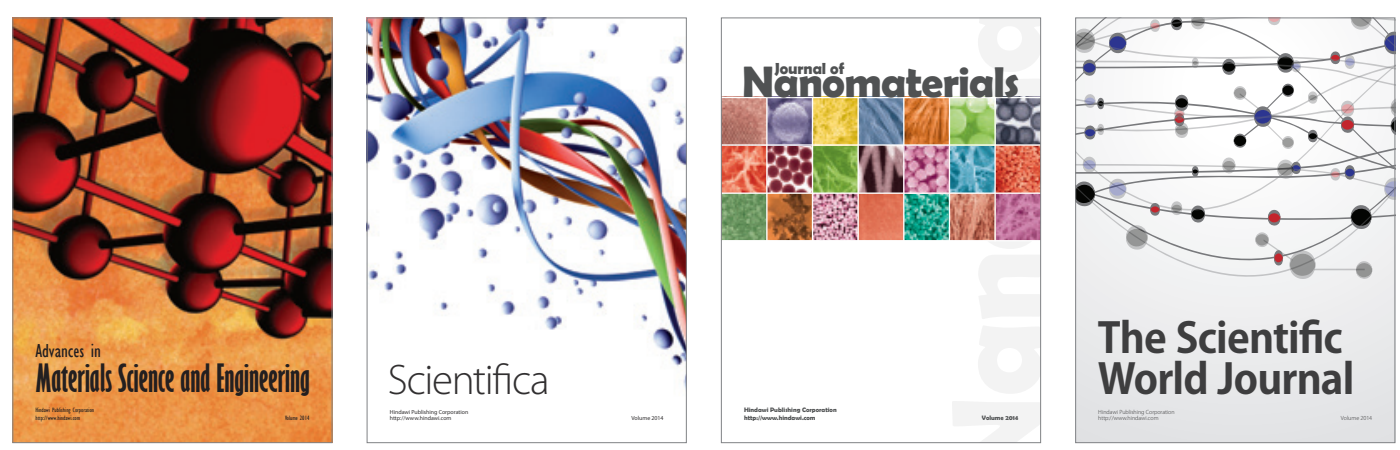

\section{The Scientific World Journal}
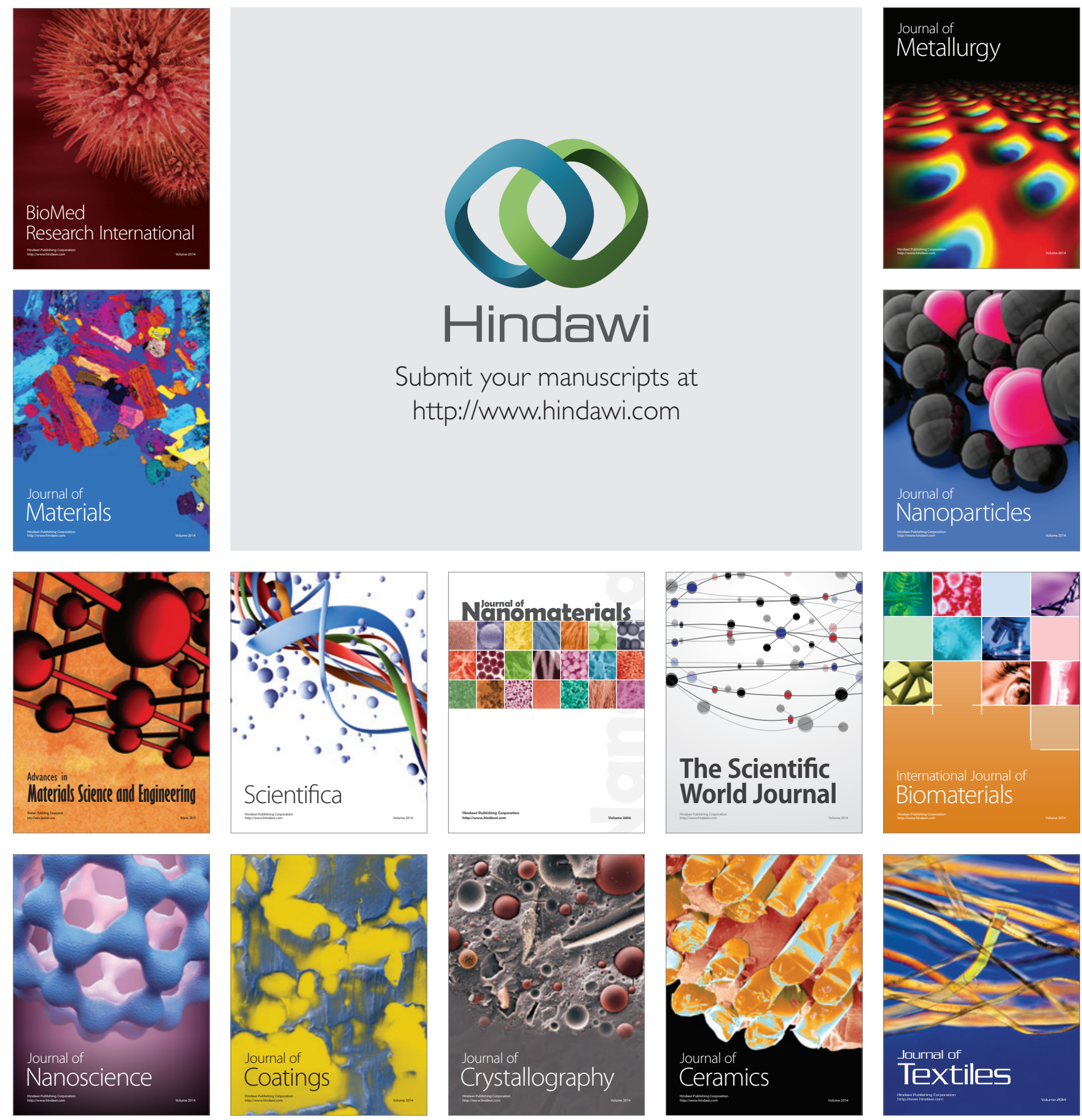